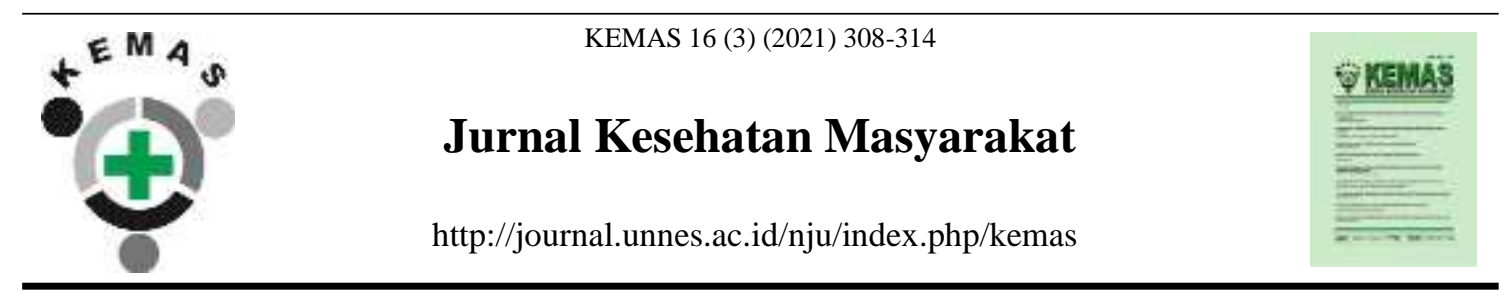

\title{
Chemical Composition and In vitro Antibacterial and Cytotoxic Effect of Nigella sativa L. Seed Extract
}

\author{
Cyuzuzo Callixte ${ }^{1}$, Heny Arwati ${ }^{2}$, Tuyishimire Irene ${ }^{3}$, Shahzad Shoukat ${ }^{1}$ \\ ${ }^{1}$ Graduate Program in Immunology, Postgraduate School, Universitas Airlangga, Indonesia \\ ${ }^{2}$ Department of Parasitology, Faculty of Medicine, Universitas Airlangga, Indonesia. \\ ${ }^{3}$ Department of Horticulture, College of Agriculture, Animal Science and Veterinary \\ Medicine, University of Rwanda, Rwanda.
}

\section{Article Info}

\section{Article History:}

Submitted October 2020

Accepted December 2020

Published March 2021

\section{Keywords:}

antibacterial, cytotoxicity,

Nigella sativa L, MIC,

inhibition zone

\section{DOI}

https://doi.org/10.15294/

kemas.v16i3.26799

\begin{abstract}
Nigella sativa L. is a plant with high medicinal profile in the treatment of diseases. This study aimed to assess the chemical composition and in vitro antibacterial and cytotoxic effect of Nigella sativa L. seed extract. Seeds were purchased from supermarket and blended into powder using electric blender. The powder was macerated with $96 \%$ methanol. The extracts were then qualitatively screened to test the presence of secondary metabolites and agar well diffusion method was employed to study the antibacterial activity of extracts. In this evaluation, 3-(4,5-dimethylthiazol-2-yl)-2,5-diphenyl tetrazolium bromide (MTT) assay was used to examine the cytotoxic effect of extract on peripheral blood mononuclear cells (PBMCs). MTT assay was done on different extract concentrations for 3 days and the results were recorded daily. The findings revealed the presence of tannins, terpenoids, steroids, saponins, alkaloids, phenolic compounds and flavonoids. The antibacterial activity was observed with the inhibition zones ranging from $11.3 \pm 1.1$ to $16.3 \pm 1.5 \mathrm{~mm}$ while the minimum inhibitory concentration (MIC) values of extract ranged between 0.5 and 1.25 $\mu \mathrm{g} / \mathrm{mL}$. The black seed extracts contain bioactive substances with germicidal activity and in vitro administration of black seed extract up to the dose of $100 \mu \mathrm{g} / \mathrm{mL}$ resulted no cytotoxic effect on PBMCs.
\end{abstract}

\section{Introduction}

The unreasonable utilization of antibiotics, long-term consumption and inappropriate treatment and prevention measures are the culprits that accelerate the resistance of different pathogenic microorganisms to commercial antibiotics (Soni \& Sosa, 2013). Moreover, the ineffectiveness of the antibiotics, they are either unavailable, expensive or the main inducers of various side effects on human body (Gracelin et al., 2012; Kaleena et al., 2011). The increased ability of pathogenic microbes to develop a resistance to the effects of antimicrobial medications is considered as a global health threat that requires extensive and collaborative researches to find an alternative source of antimicrobial products to synthetic chemical treatments (Ugur et al., 2016). Medicinal plants have many bioactive compounds with great pharmacological importance. It has been documented a long time ago that different herbs and the extracts from their diverse parts have varying degrees of antimicrobials with therapeutic potential (Islam et al., 2012). From that standpoint, World Health Organization (WHO) has permitted countries to integrate herbal medicine in their health care systems (WHO, 2013).

Nigella sativa L. is a yearly flowering dicotyledon medicinal plant which belongs to the genus Nigella L. of the family Ranunculaceae (Hamza \& Al-Harbi, 2015). It is also known as black seed or black cumin in different parts of the world (Paarakh, 2010), and a seed of blessing in the bible (Masood Alam Khan, 2019). Nigella sativa $\mathrm{L}$. seeds were scientifically documented 
to contain many natural ingredients, such as carbohydrates, chains of amino acids and sugars like glucose, rhamnose, xylose, arabinose. Some vitamins such as thiamine, niacin, riboflavin, pyridoxine, and folic acid were also reported to be present in the black seeds (El-Naggar et al., 2010). Black seeds are rich in crude fiber, minerals like $\mathrm{Ca} 2+$, $\mathrm{Fe} 3+$, and $\mathrm{K}+$, fatty acids such as oleic, linoleic, and palmitic acids, terpenoids, and alkaloids such as nigellidine, nigellimine, and nigellicine (Hassan et al., 2017). Nigella sativa seeds contains the important active compounds called thymoquinone, dithymoquinone, thymohydroquinone, thymol, carvacrol, nigellimine-N-oxide, saponins and alpha-hederin (Abraham, 2019; Aljabre et al., 2015), which have a significant function in the treatment of diabetes (Younus, 2018).

The phytoconstituent of these black seeds have been shown to have anticancer (Younus, 2018), antioxidant (Hassan et al., 2017), gastroprotective, hepatoprotective, analgesic, anti-inflammatory (Aljabre et al., 2015), antihypertensive (Ahmad et al., 2013), antidiabetic (Mohammed et al., 2019), antihistaminic, antinematodal, antischistosomal, anthelmintic, and antimicrobial impacts (Masood A. Khan et al., 2018). The black seed oil has the ability to increase the bile flow and to treat diabetes, polio, diarrhea, back pain, and rheumatoid arthritis. It also plays a major role in the treatment of various diseases like fever, headache, asthma, common cold, migraine, allergies and bronchial pulmonary disorders (Kiari et al., 2018; Kumar \& Rehman, 2019). The seed extracts of Nigella sativa L. also demonstrate the ability to inactivate MCF-7 breast cancer cells (Mahmoud \& Torchilin, 2013). After considering the traditional roles of Nigella sativa L. seeds and to acknowledge the importance of this herbal plant in the pharmaceutical field, this study is attempted to assess the chemical composition and in vitro antibacterial and cytotoxic effect of Nigella sativa L. seed extract.

\section{Methods}

The black seeds were purchased from the supermarket in Kigali, Rwanda. The seed identification was done in the laboratory of Botany, Biology department, University of Rwanda. The healthy seeds that were not showing any mechanical injury and observable rot were washed three times with distilled water and allowed to dry overnight at $40^{\circ} \mathrm{C}$. Right after drying, the seeds were blended into powder by using an electric blender. $100 \mathrm{~g}$ of powdered seed material was macerated with $96 \%$ methanol (1:5) for 3 days using rotary shaker. After extraction, the extracts were decanted and then filtered through Whatman filter paper No. 1. Crude extracts were obtained by evaporating the solvents using rotary evaporator. The yielded thick extracts were dissolved in $2 \%$ Sodium Carboxymethyl Cellulose (CMC Na 2\%) and the obtained extracts were refrigerated at $4{ }^{\circ} \mathrm{C}$ for the next stage of the research (Callixte et al.,2020).

The phytochemical screening of the extracts was systematically assessed in accordance to standard method whereby qualitative evaluations were done for different plant bioactive substances like flavonoids (Shinoda test) and steroids (Salkowski test) (Callixte et al., 2020). The other phytoconstituents that were tested are tannins (Ferric chloride test), alkaloids (Wagner test), saponins (Froth test) and phenolic compounds were examined by following the methodology published by Kumar and colleague (Kumar \& Rehman, 2019). To qualitatively screen the availability of terpenoids in the extracts, $5 \mathrm{~mL}$ of the crude extracts were mixed with $3 \mathrm{~mL}$ of chloroform followed by the addition of $2 \mathrm{~mL}$ of sulphuric acid. The formation of brown ring confirmed the availability of terpenoids in the screened extracts (Callixte et al., 2020).

The extract of Nigella sativa L. seeds was evaluated against a number of ordinal bacteria including $S$. aureus American Type Culture Collection (ATCC) 29213, Enterococcus faecalis ATCC 29212, Pseudomonas aeruginosa ATCC 27853.The evaluation of antimicrobial activity was done was on the seed extracts via the agar well diffusion method whereby every tested bacterium was aseptically cultured on MuellerHinton agar. Three created wells using a cork borer were filled with $100 \mu \mathrm{L}$ of seed extracts separately and the inoculated plates were then incubated in upright position at $37^{\circ} \mathrm{C}$ for 24 hours and dimethyl sulfoxide (DMSO) was used as a negative control and Gentamycin 
was employed as a control positive. All the tests were done in triplicate and the inhibition zones were measured in millimeters using Vernier caliper and recorded as the mean \pm standard deviation (Azizi et al., 2017).

The minimum inhibitory concentration (MIC) is normally defined as the lowest concentration that shows the ability to inhibit the visible growth of bacteria after an overnight incubation. In this study, MIC was determined by broth microdilution method according to the guidelines from the Clinical and Laboratory Standards Institute (Wayne, 2013). $10.24 \mathrm{mg}$ Nigella sativa L. seed extract was mixed with 10 $\mathrm{mL}$ of DMSO for the sake of preparing a stock solution and the serial dilutions were done ranging from $16 \mu \mathrm{g} / \mathrm{mL}$ to $0.25 \mu \mathrm{g} / \mathrm{mL}$ using Mueller-Hinton broth. A single colony of each test microorganism was diluted in $9 \mathrm{~mL}$ of peptone water and acclimatized to give the equal concentration of bacterial cells of $5 \times 105$ colony-forming units $/ \mathrm{mL}$. Following the suspension, $100 \mu \mathrm{L}$ was inoculated into each well and the Petri dishes were incubated at $35^{\circ} \mathrm{C}$ for 24 hours (Ugur et al., 2016).

During the analysis of cytotoxicity, human blood was used and the separation of peripheral blood mononuclear cells (PBMCs) and was done by using a Vacutainer which contains the cell separation medium with $\mathrm{NaNO}_{3}$ and follow the instructions as indicated by manufacturer (Rahman et al., 2014). The cytotoxic activity of Nigella sativa L. seed extract against PBMCs was evaluated on different concentrations namely 25, 50, and $100 \mu \mathrm{g} / \mathrm{mL}$, respectively following the incubation for 1,2 and 3 days using the 3-(4,5dimethylthiazol-2-yl)-2,5-diphenyl tetrazolium bromide (MTT) assay as described in various published articles (Mohammed et al., 2019). Briefly, a volume of $20 \mu \mathrm{L}$ of tetrazolium dye was added to every single well at a concentration of $5 \mathrm{mg} / \mathrm{mL}$ that was dissolved in phosphate buffer saline followed by the incubation of all plates for the duration of 4 hours at $37^{\circ} \mathrm{C}$. Subsequently, $180 \mu \mathrm{L}$ of the solution was removed from the wells and substituted with $100 \mu \mathrm{L}$ of dimethyl sulfoxide (DMSO). The rotary shaker was used for mixing the solutions and eventually the results were obtained by using the ELISA microplate reader (Mohammed et al., 2019).

\section{Results and Discussion}

The core findings of this experimental study showed the presence of bioactive substances in black seed extracts which have germicidal properties such as tannins, terpenoids, steroids, saponins, alkaloids, phenolic compounds and flavonoids as presented in table 1. This evaluation also demonstrated that the availability of phytoconstituent in Nigella sativa L. seed extracts favorized their antibacterial activity against all the tested bacteria but the extracts showed high effectiveness against Grampositive than Gram-negative bacteria as indicated in Table 2. This could be emphasized by the fact that S. aureus ATCC 29213 showed great sensitivity with $16.3 \mathrm{~mm}$ of inhibition zone and $P$. aeruginosa demonstrated low but enough sensitivity with $11.4 \mathrm{~mm}$ of inhibition diameter as shown on figure 1 . The black seed extracts didn't show any effect on the proliferation of normal human PBMCs during the period of three days and the used concentrations of extract as indicated by the results presented in table 3 .

To plainly discuss the findings of the current study, number of herbal plants have won researcher's attention due to their purified constituents which have outstanding therapeutic potentials. From that standpoint, this research was aimed to light its beams on the chemical composition and in vitro antibacterial and cytotoxic effect of Nigella sativa L. seed extract. The presence of these secondary metabolites in tested black seed extracts is in

Table 1. The Qualitative Results of the Chemical Tests of Methanolic Nigella sativa L. Seed extracts

\begin{tabular}{cccccccc}
\hline Extracts & Tannins & Steroids & Terpenoids & Saponins & Alkaloids & Phenols & Flavonoids \\
\hline $\begin{array}{c}\text { Seed } \\
\text { extracts }\end{array}$ & + & + & + & ++ & ++ & +++ & ++ \\
\hline
\end{tabular}

Source: Primary Data, 2020 
Table 2. Antibacterial Activity of Black Seed Extract Assessed by Agar Well Diffusion Method

\begin{tabular}{ccccc}
\hline \multirow{2}{*}{ Bacteria } & \multicolumn{3}{c}{ Inhibition zones(mm) } & \multirow{2}{*}{ MIC $(\boldsymbol{\mu g} / \mathbf{m L})$} \\
\cline { 2 - 4 } & $\begin{array}{c}\mathbf{1 0 0} \boldsymbol{\mu \mathbf { L } \text { of seed }} \\
\text { extracts }\end{array}$ & DMSO & $\begin{array}{c}\text { Gentamycin } \\
(\mathbf{3 0 ~} \mathbf{~ m g} / \mathbf{m L})\end{array}$ & \\
\hline S. aureus ATCC 29213 & $16.3 \pm 1.5$ & 0 & $25.6 \pm 0.5$ & 0.5 \\
E. faecalis ATCC 29212 & $14.5 \pm 0.5$ & 0 & $20.6 \pm 1.1$ & 2.5 \\
P. aeruginosa ATCC 27853 & $11.3 \pm 1.1$ & 0 & $19 \pm 0.5$ & 1.25 \\
\hline
\end{tabular}

Source: Primary Data, 2020

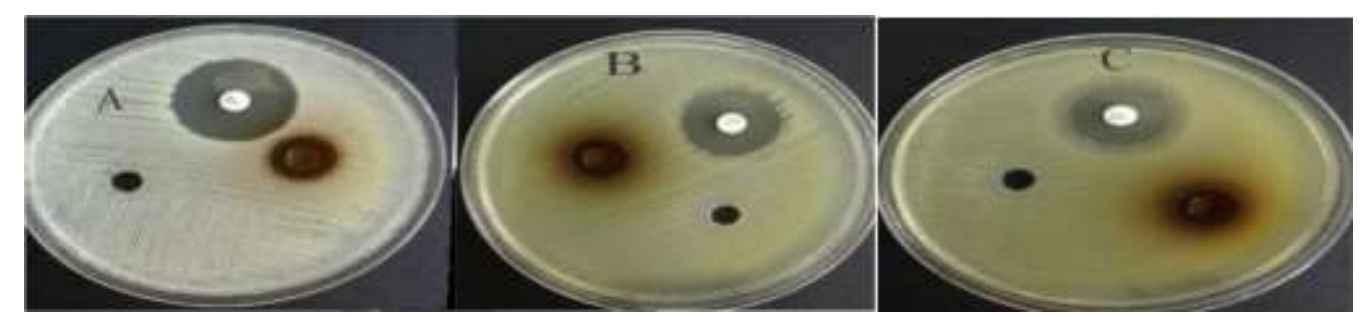

Figure 1. The Antibacterial Effect of Black Seed Extracts Against S. aureus ATCC 29213(A), E. faecalis ATCC 29212 (B) and P. aeruginosa ATCC 27853 (C)

Table 3. The Cytotoxic Effects of Nigella sativa L. Seed Extract on Normal Human PBMCs Assessed by the MTT Assay.

\begin{tabular}{ccc}
\hline Time (days) & Concentration $\boldsymbol{\mu} \mathbf{g} / \mathbf{m L}$ & Cell viability $(\%)$ \\
\hline 1 & 25 & 92 \\
& 50 & 84 \\
& 100 & 78 \\
2 & 25 & 89 \\
& 50 & 82 \\
& 100 & 75 \\
3 & 25 & 88 \\
& 50 & 80 \\
& 100 & 73 \\
\hline
\end{tabular}

Source: Primary Data, 2020

line with the other studies which reported the availability of tannins, terpenoids, steroids, saponins, alkaloids, phenolic compounds and flavonoids in Nigella sativa L. seeds (Amin \& Hosseinzadeh, 2016).

In this study, black seed extract showed remarkable effect against Gram-positive bacteria with the greatest zone of inhibition for Staphylococcus aureus ATCC 29213. This finding is in tandem with a number of previous researches which emphasized that Gram negative bacteria resist to compounds derived from plants due to the fact that they have a very strong permeability barrier, consisted of the outer membrane, which hinders the penetration of amphipathic compounds and multidrug resistance pumps that extrude toxins across this barrier (Hasan et al., 2013). This statement could be emphasized by the fact that the cell wall composition of Gram-positive and Gramnegative are different. The outer membrane of Gram-negative bacteria composed of phospholipids and lipopolysaccharides that act as a barrier that stop the entrance and reaction of most antibiotics and germicidal substances via cell envelope (Paz et al., 2015).

The antimicrobial activity of black seed extract is also attributed to the availability of thymoquinone and its derivative compounds like thymohydroquinone, dithymoquinone, and thymol (Ugur et al., 2016). Thymoquinone itself was documented to own free rotation 
bonds which enable it to rotate and this conformations in $\mathrm{CH} 3$ group allows it and other bioactive substances present in black seed to change their shapes, interacts with bacteria and enter or cross their boundary and eventually kill them (Woo et al., 2012). It was as well reported by another study findings that the hydrophobic bioactive substances damage the bacterial plasma membrane, increases cell permeability, disrupt biomolecule synthesis and damage integrity of bacterial cell walls (Scandorieiro et al., 2016).

The extracts inhibit the growth of microorganisms by causing the leakage of proteins and some enzymes from the cell. Flavonoids as one of the secondary metabolites present in black seeds have 3-O-octanoylepicatechin which enhance membrane affinity of their long acyl chains. From that perspective, flavonoids that lack hydroxyl groups on their B rings are the most effective substances to hinder microbial membranes than those with hydroxyl $(\mathrm{OH})$ groups (Callixte et al., 2020). Gentamycin as a commercial antibiotic exhibited great bactericidal activity than the examined black seed extracts as clearly presented in table 2 . As reported from previous studies, the observed germicidal potential of antibiotic than the plant extracts may be attributed to the fact that antibiotics are purified in natural ways and kept in refined states whereas extracts were used in crude forms (Nassima et al., 2019).

In this preliminary study, the black seed extracts didn't show any effect on the proliferation of normal human PBMCs during the period of three days and the used concentrations of extract as demonstrated by results in table 3 . This is in tandem with the results of Ugur and Colleagues which did not notice any cytotoxic influence on the proliferation of gingival fibroblasts (Ugur et al., 2016). It is also in conformity with the results published by Mohammed and colleagues that black seed extracts do not have any cytotoxic effect on normal cells (Mohammed et al., 2019). This finding is also in agreement with the previously published in vivo studies where the exposure of cultured rat cortical neurons on different concentrations of Nigella sativa L. methanolic seed extract at various times did not induce any toxicity (Nehar et al., 2015).
However, this is in controversy with another study that disclosed that the administration of black seed extract increased phagocytic activity of peritoneal macrophages, hepatotoxicity and nephrotoxicity (Mansour et al., 2001; Swamy \& Tan, 2000; Yildiz et al., 2010).

The lack of black seed toxicity on PBMCs is in line with the findings obtained by other research which highlighted that the intraperitoneal administration of Nigella sativa L. seed extracts for the duration of 5 days did not affect the enzyme levels and change the metabolites in the liver and kidney of rats (Amin \& Hosseinzadeh, 2016). This could be assisted by the other research results that reported no observable changes in hepatic enzymes levels such as aspartate-aminotransferase, alanineaminotransferase, gamma-glutamyltransferase after 288 days of treatment (Zaoui et al., 2002). The safety of black seed derivatives was also observed in another study where the researchers feed Hibro broiler chicks with a diet that contains 20 or $100 \mathrm{~g} / \mathrm{kg}$ of Nigella sativa

L. ground seeds for the duration of 84 days and did not adversely affect their growth (AlHomidan et al., 2002). The obtained findings from this assessment agree with the published data reporting that Nigella sativa L. seed extracts have a wide and trustworthy margin of safety (Dollah et al., 2013).

\section{Conclusion}

The conclusion that can be drawn is that the findings of the current study constitute helpful evidence to validate folkloric importance of Nigella sativa L. seed extract as herbal remedy for various bacterial infections due to the presence of secondary metabolites with antibacterial activities. These results of this preliminary assessment also conclude that the popular use of black seed extract did not cause any toxicity effect on normal human peripheral blood mononuclear cells and are safe to be utilized for various therapeutic purposes.

\section{References}

Abraham, A.O., 2019. Antimicrobial Activity of N-Hexane Extract of Nigella Sativa against Some Pathogenic Bacteria. American Journal of Biomedical Science \& Research, 6(5), pp.430-434. 
Ahmad, A., Husain, A., Mujeeb, M., Khan, S.A., Najmi, A.K., Siddique, N.A., Damanhouri, Z.A., \& Anwar, F., 2013. A Review on Therapeutic Potential of Nigella sativa: A Miracle Herb. Asian Pacific Journal of Tropical Biomedicine, 3(5), pp.337-352.

Al-Homidan, A., Al-Qarawi, A.A., Al-Waily, S.A., \& Adam, S.E.I., 2002. Response of Broiler Chicks to Dietary Rhazya stricta and Nigella sativa. British Poultry Science, 43(2), pp.291- 296.

Aljabre, S.H.M., Alakloby, O.M., \& Randhawa, M.A., 2015. Dermatological Effects of Nigella sativa. Journal of Dermatology \& Dermatologic Surgery, 19(2), pp.92-98.

Amin, B., \& Hosseinzadeh, H., 2016. Black Cumin (Nigella sativa) and Its Active Constituent, Thymoquinone: An Overview on the Analgesic and Anti-inflammatory Effects. Planta Medica, 82(1-2), pp.8-16.

Azizi, S., Shahri, M.M., Rahman, H.S., Rahim, R.A., Rasedee, A., \& Mohamad, R., 2017. Green Synthesis Palladium Nanoparticles Mediated by White Tea (Camellia sinensis) Extract with Antioxidant, Antibacterial, and Antiproliferative Activities Toward the Human Leukemia (MOLT-4) Cell Line. International Journal of Nanomedicine, 12, pp.8841-8853.

Callixte, C., \& Dusabimana, J.D., Ma'ruf, A., Dachlan, Y.P., Sensusiati, A.D., Daniel, N.W.E., 2020. Phytoconstituent Analysis and Antibacterial Potential of Epicarp Extracts from Mature Fruits of Persea americana Mill. Molecular and Cellular Biomedical Sciences, 4(2), pp.94-99.

Callixte, C., Baptiste, N.J., \& Arwati, H., 2020. Phytochemical Screening and Antimicrobial Activities of Methanolic and Aqueous Leaf Extracts of Carica papaya Grown in Rwanda. Molecular and Cellular Biomedical Sciences, 4(1), pp.39.

Dollah, M.A., Parhizkar, S., Latiff, L.A., \& Hassan, M.H.B., 2013. Toxicity Effect of Nigella sativa on the Liver Function of Rats. Advanced Pharmaceutical Bulletin, 3(1), pp.97-102.

El-Naggar, T., Gómez-Serranillos, M. P., Palomino, O. M., Arce, C., \& Carretero, M.E., 2010. Nigella sativa L. Seed Extract Modulates the Neurotransmitter Amino Acids Release in Cultured Neurons in Vitro. Journal of Biomedicine and Biotechnology, 2010.

Gracelin, D.H.S., Britto, J., De-eya, P.B., \& Kumar, R., 2012. Antibacterial Screening Of A Few Medicinal Ferns Against Antibiotic Resistant Phyto Pathogen. International Journal of
Pharmaceutical Sciences and Research, 3(03), pp.868-873.

Hamza, R.Z., \& Al-Harbi, M.S., 2015. Amelioration of Paracetamol Hepatotoxicity and Oxidative Stress on Mice Liver with Silymarin and Nigella sativa Extract Supplements. Asian Pacific Journal of Tropical Biomedicine, 5(7), pp.521-531.

Hasan, N.A., Nawahwi, M.Z., \& Malek, H.A., 2013. Antimicrobial Activity of Nigella sativa Seed Extract. Sains Malaysiana, 42(2), pp.143-147.

Hassan, M.Q., Akhtar, M., Ahmed, S., Ahmad, A., \& Najmi, A.K., 2017. Nigella sativa Protects Against Isoproterenol-induced Myocardial Infarction by Alleviating Oxidative Stress, Biochemical Alterations and Histological Damage. Asian Pacific Journal of Tropical Biomedicine, 7(4), pp.294-299.

Islam, M.H., Ahmad, I.Z., \& Salman, M.T., 2012. Antibacterial Activity of Nigella sativa Seed in Various Germination Phases on Clinical Bacterial Strains Isolated from Human Patients. E3 Journal of Biotechnology and Pharmaceutical Research, 4, pp.8-13.

Kaleena, P.K., Philip, D., Valivittan, K., \& Girish Kumar, C.P., 2011. Phytochemical Screening and Antimicrobial Activity of Sansevieria roxburghiana Schult. and Schult. F. Middle-East Journal of Scientific Research, 10(4), pp.512-518.

Khan, M.A., Aldebasi, Y.H., Alsuhaibani, S.A., AlSahli, M.A., Alzohairy, M.A., Khan, A., \& Younus, H., 2018. Therapeutic Potential of Thymoquinone Liposomes Against the Systemic Infection of Candida albicans in Diabetic Mice. PLoS ONE, 13(12), pp.1-17.

Khan, M.A., 2019. Thymoquinone, A Constituent of Prophetic Medicine-black Seed, is a Miracle Therapeutic Molecule Against Multiple Diseases. International Journal of Health Sciences, 13(1), pp.1-2.

Kiari, F.Z., Meddah, B., \& Tir, T.M.A., 2018. In Vitro Study on the Activity of Essential Oil and Methanolic Extract from Algerian Nigella sativa L. Seeds on the Growth Kinetics of Micro-Organisms Isolated from the Buccal Cavities of Periodontal Patients. Saudi Dental Journal, 30(4), pp.312-323.

Kumar, A., \& Rehman, H., 2019. Antibacterial, Antioxidant, Cytotoxicity and Qualitative Phyto- Chemical Evaluation of Seed Extracts of Nigella sativa and Its Introduction.

Mahmoud, S.S., \& Torchilin, V.P., 2013. Hormetic/ Cytotoxic Effects of Nigella sativa Seed Alcoholic and Aqueous Extracts on MCF-7 Breast Cancer Cells Alone or in Combination 
with Doxorubicin. Cell Biochemistry and

Biophysics, 66(3), pp.451-460.

Mansour, M.A., Ginawi, O.T., El-Hadiyah, T., ElKhatib, A.S., Al-Shabanah, O.A., \& AlSawaf, H.A., 2001. Effects of Volatile Oil Constituents of Nigella sativa on Carbon Tetrachloride-Induced Hepatotoxicity in Mice: Evidence for Antioxidant Effects of Thymoquinone. Research Communications in Molecular Pathology and Pharmacology, 110(3-4), pp.239-251.

Mohammed, S.J., Amin, H.H.H., Aziz, S.B., Sha, A.M., Hassan, S., Abdul Aziz, J.M., \& Rahman, H.S., 2019. Structural Characterization, Antimicrobial Activity, and in Vitro Cytotoxicity Effect of Black Seed Oil. Evidence-Based Complementary and Alternative Medicine, 2019.

Nassima, B., Nassima, B., \& Riadh, K., 2019. Antimicrobial and Antibiofilm Activities of Phenolic Compounds Extracted from Populus nigra and Populus Alba Buds (Algeria). Brazilian Journal of Pharmaceutical Sciences, 55.

Nehar, S., Rani, P., Kumar, C., Kauser, H., \& Alam, I., 2015. Evaluation on Cytotoxicity of Ethanolic Extract of Nigella sativa Seed. American Journal of Ethnomedicine, 2(5), pp.276-283.

Paarakh, P.M., 2010. Nigella sativa Linn.- A Comprehensive Review. Indian Journal of Natural Products and Resources, 1(4), pp.409-429.

Paz, M., Gúllon, P., Barroso, M.F., Carvalho, A.P., Domingues, V.F., Gomes, A.M., Becker, H., Longhinotti, E., \& Delerue-Matos, C., 2015. Brazilian Fruit Pulps as Functional Foods and Additives: Evaluation of Bioactive Compounds. Food Chemistry, 172, pp.462468.

Rahman, H.S., Rasedee, A., Abdul, A.B., Zeenathul, N.A., Othman, H.H., Yeap, S.K., How, C.W., \& Wan, N.H., W, A.G., 2014. Zerumboneloaded Nanostructured Lipid Carrier Induces G2/M Cell Cycle Arrest and Apoptosis Via Mitochondrial Pathway in a Human Lymphoblastic Leukemia Cell Line. International Journal of Nanomedicine, 9(1), pp.527-538.

Scandorieiro, S., de Camargo, L.C., Lancheros, C.A.C., Yamada-Ogatta, S.F., Nakamura, C.V., de Oliveira, A.G., Andrade, C.G.T.J.,
Duran, N., Nakazato, G., \& Kobayashi, R.K.T., 2016. Synergistic and Additive Effect of Oregano Essential Oil and Biological Silver Nanoparticles Against Multidrug-resistant Bacterial Strains. Frontiers in Microbiology, 7, pp.1-14.

Soni, A., \& Sosa, S., 2013. Phytochemical Analysis and Free Radical Scavenging Potential of Herbal and Medicinal Plant Extracts. Journal of Pharmacognosy and Phytochemistry JPP, 22(24), pp.22-29.

Swamy, S.M.K., \& Tan, B.K.H., 2000. Cytotoxic and Immunopotentiating Effects of Ethanolic Extract of Nigella sativa L. seeds. Journal of Ethnopharmacology, 70(1), pp.1-7.

Ugur, A. R., Dagi, H.T., Ozturk, B., Tekin, G., \& Findik, D., 2016. Assessment of in Vitro Antibacterial Activity and Cytotoxicity Effect of Nigella sativa oil. Pharmacognosy Magazine, 12(47), pp.S471-S474.

Wayne, P., 2013. M100-S23 Performance Standards for Antimicrobial (Issue January).

Woo, C.C., Kumar, A.P., Sethi, G., \& Tan, K.H.B., 2012. Thymoquinone: Potential Cure for Inflammatory Disorders and Cancer. Biochemical Pharmacology, 83(4), pp.443451.

World Health Organization (WHO)., 2013. WHO Traditional Medicine Strategy 2014-2023. World Health Organization (WHO), pp.176.

Yildiz, F., Coban, S., Terzi, A., Savas, M., Bitiren, M., Celik, H., \& Aksoy, N., 2010. Protective Effects of Nigella Sativa Against Ischemia-reperfusion Injury of Kidneys. Renal Failure, 32(1), pp.126-131.

Younus, H., 2018. Younus, H., 2018. Molecular and Therapeutic actions of Thymoquinone Actions of Thymoquinone, Livre. (I. Younus, Hina (Interdisciplinary Biotechnology Unit Aligarh Muslim University Aligarh, Uttar Pradesh (ed.); 1st ed.). Berlin, Germany ,Springer US.

Zaoui, A., Cherrah, Y., Alaoui, K., Mahassine, N., Amarouch, H., \& Hassar, M., 2002. Effects of Nigella sativa Fixed Oil on Blood Homeostasis in Rat. Journal of Ethnopharmacology, 79(1), pp.23-26. 